\title{
Emancipación e indagación aportes del pensamiento pedagógico de Valentín Letelier para una discusión de la categoría de acto didáctico
}

ADRIÁN RODRIGO BAEZA ARAYA

Universidad de Chile, Santiago de Chile, Chile

\section{RESUMEN}

El objetivo del presente artículo es recuperar las ideas pedagógicas del pensador chileno Valentín Letelier (1852-1919), desde un punto de vista crítico al estado del arte en torno a la noción de acto didáctico. Se examina, en primer lugar, el marco histórico dentro del cual Letelier produce su principal texto pedagógico: Filosofía de la educación (1892). Tomándose como base diversos textos del pensador, se caracteriza primeramente su discurso pedagógico, desde el punto de vista didáctico, para luego tomar distancia de la arista de la construcción de una pedagogía del desarrollo. En dicho proceso, se focaliza constantemente el ejercicio de resistencia teórica de Letelier -a veces consciente, a veces no- frente a los discursos metropolitanos. Aprovechando ideas de Said (2001) y de Jorge Medina (2006) sobre la resistencia, se explicitan los posicionamientos didácticos visibles de Letelier en sus reinscripciones del discurso europeo, en la reintegración de sus fisuras, en sus intervenciones e interferencias alegóricas, al mismo tiempo que en sus deudas y tributos con esos discursos metropolitanos. Desde esta perspectiva, el pensamiento de Letelier es considerado una manera de resistencia que permite pensar configuraciones más auténticas del evento didáctico que las existentes en el consenso teórico contemporáneo de una didáctica del objeto.

Valentín Letelier; acto didáctico; didáctica; desarrollo; emancipación. 


\section{EMANCIPATION AND RESEARCH: CONTRIBUTIONS OF VALENTÍN LETELIER'S PEDAGOGICAL THOUGHTS TO DISCUSS THE DIDACTIC EVENT CATEGORY}

\section{ABSTRACT}

This paper aims to value the educational ideas of chilean thinker Valentín Letelier (1852-1919), with a critical view on the state of art of the notion of didactic event. First of all, we take a look at the historical framework that Letelier produced his main pedagogical text: Filosofía de la educación (1892). From this and other texts I outline the main features of his pedagogical discourse from a didactic standpoint. Then, I see it in relation to the problem of constituting pedagogy of development. I will constantly focus on Letelier's exercise of theoretic resistance, sometimes intentional, others unintentional, to metropolitan discourses. Benefited from Said's (2001) and Jorge Medina's (2006) ideas about resistance, I search for his didactic positions which are legible in reinscriptions and reintegrations of european discourse and its fissures, as well as in interventions and allegoric interferences. His debts with, and tributes to, his metropolitan referents are referred to as well. From this perspective, the thought of Letelier is considered as a way of resistance to think more authentic sociocultural configurations of the didactic event than those in the existing contemporary theoretical consensus of object centered didactics.

\section{KEYWORDS}

Valentín Letelier; didactic event; didactics; development; emancipation.

\section{EMANCIPAÇÃO E INQUÉRITO: CONTRIBUIÇÕES DO PENSAMENTO PEDAGÓGICO DE VALENTÍN LETELIER PARA A DISCUSSÃO DA CATEGORIA DE ATO DIDÁTICO}

\section{RESUMO}

Este artigo tem como objetivo recuperar as ideias pedagógicas do pensador chileno Valentín Letelier (1852-1919), com um olhar crítico ao estado da arte em torno da noção de ato didático. Examina-se, em primeiro lugar, o marco histórico dentro do qual Letelier produz seu principal texto pedagógico: Filosofía de la educación (1892). Tomando-se por base diversos textos do pensador, caracteriza-se primeiramente o seu discurso pedagógico, do ponto de vista didático, para depois se tomar distância da arista da construção de uma pedagogia do desenvolvimento. Nesse processo, focaliza-se constantemente o exercício de resistência teórica de Letelier, às vezes consciente, às vezes não, diante dos discursos metropolitanos. Aproveitando as ideias de Said (2001) e Jorge Medina (2006) sobre a resistência, explicitam-se os posicionamentos didáticos visíveis de Letelier em suas reinscrições do discurso europeu, na reintegração de suas fissuras, em suas intervenções e interferências alegóricas, e ao mesmo tempo em suas dívidas e tributos sobre esses discursos metropolitanos. Nessa perspectiva, o pensamento de Letelier é considerado uma maneira de resistência, que permite pensar configurações do evento didático mais autênticas que as existentes no consenso teórico-contemporâneo de uma didática do objeto.

PALAVRAS-CHAVE

Valentín Letelier; ato didático; didática; desenvolvimento; emancipação. 


\section{INTRODUCCIÓN}

Por debajo de las discontinuidades teóricas que distinguen entre una concepción lineal del acto didáctico concebido bajo el lema "enseñanza-aprendizaje" (Camilloni; Basabe; Feeney, 2008) y otra triádica, con una fuerte impronta gnoseológica celebrada por Ausubel, ${ }^{1}$ cuyo fruto ha sido otorgar a las disciplinas del saber una función epistemológicamente clave que fragmenta el campo didáctico, puede proponerse la existencia de una matriz metateórica de continuidades discursivas. Las mismas han sido históricamente construidas a lo largo del desarrollo del pensamiento pedagógico metropolitano de forma paralela a las que lo constituyen teóricamente y que han sido explicitadas por Narodowski (1994). Claves en la configuración de la matriz canónica, y presentes por igual en el consenso triádico en torno al acto didáctico, resultan la mantención de los roles asimétricos profesor-alumno con exclusión de otros roles, la categoría de aprendizaje, la infantilización permanente del educando como sujeto sin poder decisional dependiente de un sujeto pleno ${ }^{2}$ (más civilizado, más adulto o más sabio), y la distinción anómala entre mundo de la vida y mundo del aula.

Todo ello opera como centro gravitacional de los procesos pedagógicos evitando la dispersión de sus fuerzas mediante el control de un espacio constituido por la categoría de "aprendizaje" y una exclusión sistemática de toda consideración del desarrollo que pueda introducir lo político -sobre todo como poder decisional-y la historicidad de todo acto formativo -sobre todo como actualización inmediata del futuro en el presente de aula-. ${ }^{3}$ La matriz así conformada, a la cual llamaremos "acto didáctico canónico", podemos pensarla, siguiendo la idea bajtiniana de la condición semiótica de la conciencia, como matriz de ideologemas (Voloshinov, 1976). Esa matriz estabiliza cierta forma metateórica de estructurar el acto didáctico como modo de vinculación entre sujetos y mundo desde la posición enunciativa de la metrópoli, llevando marcas de una dimensión imperial bajo el estandarte de la evangelización y, más tarde, de la misión civilizadora: la empresa imperial, como ha dicho Said, se presentó a sí misma como empresa educativa (Said, 2001, p. 346).

1 Dicen Ausubel y sus colaboradores que "relacionada con el creciente hincapié en el adiestramiento intelectual, está la reciente y alentadora tendencia a concederle mayor valor a la adquisición de conocimiento como un fin significativo en sí mismo" (Ausubel; Novak; Hanesian, 1983, p. 43).

2 La figura del educando es, en el discurso pedagógico metropolitano, construida constantemente en confrontación con otro no europeo: los bárbaros en la pedagogía de la evangelización de la conquista, los americanos para Comenio, los salvajes para Rousseau, los bárbaros para Pestalozzi; otra vez los salvajes para Herbert Spencer, etc., hasta el "hombre primitivo" de Piaget (Vygotski, 1995, p. 87).

3 La despolitización y deshistorización se inauguran sosteniendo que "el valor de gran parte del aprendizaje escolar solo puede defenderse con fundamente en que mejora en los alumnos la comprensión de ideas importantes de la cultura a que pertenecen; y no porque tenga, aun remotamente, determinados usos o implicaciones prácticas"(Ausubel; Novak; Hanesian, 1983, p. 43). 
En Latinoamérica, la conexión entre la pedagogía, el imperialismo y la cultura como "campo de batalla" aparece claramente cuando nos detenemos a considerar la relación complementaria establecida durante la segunda mitad del siglo XIX entre la consolidación de los gobiernos oligárquicos en Latinoamérica, el proceso de construcción de los sistemas educativos nacionales ${ }^{4}$ y el posicionamiento de las economías regionales en el orden mundial desde el lugar de la exportación de materias primas.

En el marco tendido por dicha matriz, el consenso teórico imperante en el pensamiento didáctico actual entiende que el núcleo fundamental del hecho educativo está constituido por una tríada de elementos que comprende lo esencial del mismo (Fanon, 1963, p. 47). Esa tríada de consenso, compuesta habitualmente por los polos profesor-alumno-conocimiento, ${ }^{5}$ cuyo origen más probable son las ideas ausubelianas en torno al aprendizaje significativo y la función ingenieril ${ }^{6} \mathrm{de}$ la psicología de la educación para el campo educativo (Ausubel; Novak; Hanesian, 1983 , p. 26), se ha entendido a menudo como la relación establecida entre el conocimiento (o saber) con el aprendizaje (o el alumno) y la enseñanza (o el profesor), como lo vemos de modo evidente en el trabajo de Yves Chevallard en los años ochenta con su noción de "sistema didáctico"(2009). Posteriormente, es visible también en el pensamiento argentino de los años 1990, con Marta Souto (1993, p. 42) o Alicia Camilloni (2008) y Edith Litwin (2008).

Recientemente, en el trabajo del Grupo de Trabajo sobre Políticas Educativas y Acontecimiento Didáctico (PEAD), de la Universidad de La República de Uruguay, observamos la permanencia de este constructo en el desarrollo de las idea de "fantasía didáctica" de Chevallard a la luz del psicoanálisis en autores como Paola Behetti (2007) y Eloísa Bordoli (2007). El efecto de la tríada es dar una impronta gnoseológica totalizante al proceso formativo que acaba dando excesiva autoridad a la epistemología de las disciplinas del curriculum en desmedro de las dimensiones cultural, social, política, subjetiva que éste pueda tener, poniendo, por demás, en segundo lugar la subjetividad de los participantes, presentes en el acto pedagógico principalmente como intelectos antes que como actores sociales.

Desde una perspectiva filosófica, Jorge Medina, aun cuando es parte también de este consenso, aporta algunas salidas. Aborda la crítica de la educación hegemónica

4 "Otro poder que la oligarquía tiene en sus manos - señala Marcello Carmagnani- es el poder cultural del que se sirve para reforzar su preeminencia social. No hay que olvidar que hacia 1880 más de los dos tercios de la población total de cualquier país latinoamericano era analfabeta. Es más, si observamos el caso de Argentina veremos que aún en 1890, cuando su población es de 3.500 .000 habitantes, solamente tiene 4.000 alumnos inscritos en las escuelas medias y 963 estudiantes en las distintas Universidades. Similar, si no peor, es la situación de otros países latinoamericanos, más atrasados que Argentina en este aspecto" (Carmagnani, 1984, p. 60).

5 Otras variantes pueden ser la muy socorrida de enseñanza-aprendizaje-conocimiento, la de enseñante -saber- alumno de Chevallard y la de enseñanza, aprendizaje, contenido cultural, de María Loreto Nervi y Hugo Nervi.

6 "Pocas personas irían en contra de la afirmación de que la educación es una ciencia aplicada o de ingeniería” (Ausubel; Novak; Hanesian, 1983, p. 26). 
en El malestar en la pedagogía (2006), donde se hace parte de la crítica a la constitución fragmentada de la subjetividad en la modernidad instrumental, la que se asentó en el campo de la educación de la mano del positivismo. Medina se une a quienes han denunciado los efectos perversos de la disociación del sujeto en esta matriz cultural (Fanon, 1963; Aguilera, 1991; Lander, 2000; Rojo, 2008) y busca los espacios de resistencia disponibles para un replanteamiento y una posterior superación de la "orfandad" de la pedagogía. La limitación de su propuesta es que acepta el consenso didáctico que hemos indicado como "un diagrama sencillo: la unidad conformada por los tres protagonistas básicos del acto pedagógico: docente, alumno, conocimien to" que "facilitará el pensamiento trascendiendo la clasificación didáctica en objetivos, contenidos, técnicas, métodos, actividades, etc." (Medina, 2006, p. 65), con la esperanza de poder "penetrar en el interior del acto pedagógico, como aquella antigua trama relacional que en su interior guarda nuevas posibilidades de respuesta en forma potencial" (idem, p. 53).

La deshumanización se combate mediante la posibilidad del encuentro con el otro, encuentro como posibilidad de humanización donde la subjetividad es liberada por medio del juego y la poética docente, manifestados en interferencias alegóricas que rompen los lindes del discurso hegemônico e instauran nuevas posibilidades mediante el poder disruptivo de la metáfora. Sin embargo, al ocurrir en un marco vincular dado por la tríada canónica del acto didáctico, no es raro que tales manifestaciones solo aparezcan como posibles de modo asimismo fragmentario, disruptivo, dentro de la lógica de la matriz disociativa que es verdadero corazón del modelo canónico.

\section{ACTO DIDÁCTICO Y RESISTENCIA}

Las rupturas contraculturales y, en particular, el sentido de humanización, aportan una vía fundamental de salida hacia formulaciones más auténticas y menos escolarizadas del acto didáctico si son llevados a una comprensión más allá del campo de determinaciones escolares comprendidas en el acto canónico, ampliando la relación pedagógica, como sugería Gramsci (1971, p. 31-32), a toda relación de hegemonía. Pero, para que tal cosa sea posible en la praxis educativa, es importante que se vea acompañada de un replanteamiento tanto teórico (referente a la historización y cuestionamiento de la didáctica como disciplina) como metateórico, es decir, como una praxis intelectual de doble negación (Germán, 2008, p. 14): la práctica de una necesaria crítica y autocrítica de su propio lugar enunciativo, pues "si la teoría ha de ir más allá del legado positivista de la neutralidad, debe desarrollar la capacidad de la metateoría. Esto es, debe reconocer la tendencia de los intereses que representa y ser capaz de reflexionar críticamente tanto en el desarrollo histórico o génesis de tales intereses como en las limitaciones que éstos pueden presentar dentro de ciertos contextos históricos y sociales" (Giroux, 2004, p. 38).

7 "Un fantasma - parafrasea Medina- recorre la pedagogía. Es el fantasma de la orfandad. La pedagogía está huérfana de juego, de cuerpo y de poética” (Medina, 2006, p. 33). 
No basta, por lo tanto, reconocer la dimensión política del acto didáctico como hizo Souto (1993) en los años 1980 , pues en sí mismo esto no supone un cuestionamiento radical de la tríada canónica. Crucial se vuelve, en primer lugar, redefinir el acto didáctico como matriz básica del establecimiento de vínculos culturales comunitarios, es decir, considerar en la comprensión de lo didáctico que es su dimensión cultural lo que permite el establecimiento de una serie de vínculos constitutivos y constituyentes implicados en los actos formativos, dada la "estrecha vinculación que se percibe entre los discursos económicos, los proyectos políticos y las prácticas educativas" (Noguera; Ramírez, 2012, p. 17). Para Cerletti, en esta línea de interpretación, "la posibilidad de reproducción de las sociedades se dirime en el sostenimiento de un vínculo cultural (en tanto difusión de las tradiciones, las costumbres, las prácticas sociales, etc.), pero también, y fundamentalmente, político (en cuanto reaseguro del lazo social constituido)". Para tales efectos constituyentes de la sociabilidad, "la educación institucionalizada reafirma, además -y sobre todo-, una concepción del Estado, un conjunto de saberes admitidos y el lugar que corresponde o puede corresponder a cada uno de los miembros en una comunidad" (Cerletti, 2008, p. 16).

Todo aquello, según Noguera, habría sido una constante de la modernidad, habida cuenta de que en lo relativo al "gobernamiento" ${ }^{8}$ se trataba de problemas profundamente pedagógicos. Desde el surgimiento simultáneo de la razón de Estado y de la didáctica, ${ }^{9}$ y a lo largo de toda la modernidad, gobernar es educar, según Noguera y Ramírez, como lo fue para Letelier a fines del siglo XIX. Dicha constante marca la modernidad, leída como "sociedad educativa", en tanto:

sociedad de la pampedia, una sociedad en que, por primera vez en la historia de la humanidad, se pretendió que todos sus integrantes fuesen sometidos a una diversidad de procesos de enseñanza y estuviesen dispuestos a aprender durante

8 Noguera y Ramírez (2012, p. 19) toman de Foucault el concepto de "gobernamiento" o "gubernamentalidad"para aludir a la práctica o acto de gobernar, que se fue transformando, entre la Edad Media y principios del siglo XVIII, desde formas soberanas del ejercicio de poder a la formación de dispositivos disciplinarios y, entre el siglo XVIII a la actualidad, desde tales dispositivos disciplinantes a los dispositivos de seguridad en el marco del liberalismo. A cada etapa corresponde, según estos autores, una concepción del Estado: la del Estado enseñante, para la primera, y la del Estado educador, para la segunda, las cuales corresponden a las dos etapas en que según Foucault la gubernamentalidad sufre desplazamientos, primero entre la Edad Media y principios del siglo XVIII y desde allí al siglo XIX. Agregan estos autores una tercera modalidad,la de la sociedad del aprendizaje, centrada en el énfasis en el individuo que aprende, un diseño en el que perciben la "gubernamentalidad neoliberal".

9 Es posible hacer un matiz a este origen que une didáctica como disciplina y razón de Estado, en tanto Estado moderno o Estado nacional en el cual parecen haber estado pensando Noguera y Ramírez. Ese matiz es el de relación, anterior, entre razón imperial y discurso pedagógico visible en el discurso de los evangelizadores de Indias durante el siglo XVI. Un buen ejemplo de esto es el De procuranda indorum salute, de José de Acosta (1588). 
toda su vida como condición para alcanzar una determinada forma deseable de ser humano. (Noguera; Ramírez, 2012, p. 19)

En segundo lugar, desde aquí se percibe una apertura interesante de esta idea que liga los órdenes del gobierno y la educación y permitiría mostrar las funciones del segundo para con el primero. En lo metateórico, la nota de cautela antiescolarizante que conlleva nos pone frente a la necesidad de vislumbrar esa articulación no sólo en la praxis eduacional, sino también en la praxis teórico intelectual dentro del campo pedagógico, contribuyendo al debate desde la historización del pensamiento didáctico y, concretamente, del forjado desde Latinoamérica en diálogos diversos con el metropolitano. Para dicha lectura de las relaciones entre pensamiento pedagógico latinoamericano y metropolitano, se vuelve relevante considerar lo relativo a la resistencia en el pensamiento pedagógico de nuestros intelectuales latinoamericanos, entre ellos, el de Letelier. La resistencia, distinta de la simple oposición, siempre metropolitana y con la cual puede estar articulada (Said, 2001, p. 312), puede entenderse como una parte de la lucha por la humanización en contra de la fragmentación de la unidad del sujeto, la que puede verificarse en tres alcances: el sujeto, la colectividad y la humanidad (Fanon, 1963, p. 290-291). Cada uno de esos alcances es visible en el hecho didáctico, dentro del cual se ha jugado una cierta construcción del sujeto, del colectivo formado por los educandos y de la cultura.

Entre las estrategias de la resistencia podemos incluir cuatro, dos de las cuales serían, valiéndonos de Edward Said la reinscripción, en la cual se debe "recobrar formas ya establecidas por la cultura del imperio o, al menos, infiltradas o influidas por él", y que son sometidas a un "celo reinterpretativo" (Said, 2001, p. 327) y la intervención, donde se produce una infiltración con "formas, totalmente inéditas dentro de la cultura occidental, de las intervenciones de artistas y estudiosos no europeos" (idem, p. 330). Jorge Medina detecta, en lo que para Fanon era el primer nivel del programa de liberación, una dimensión de resistencia enfocada concretamente en combatir los efectos de la matriz fragmentadora de la cultura occidental en el campo educativo: "una cultura de la fragmentación, de la disociación del ser humano, que se refleja y se esboza en la superficie de los discursos en un conjunto de variadas y falsas antinomias: razón-afectos; goceesfuerzo; trabajo-placer; cuerpo-mente; persona-rol; teoría-práctica" (Medina, 2006 , p. 35). La lucha que exige es cotidiana y contracultural y se da en la práctica docente, sea como resistencia de los alumnos a hacer lo que los educadores quieren, sea como un pensamiento del profesor "que aún no es para sî". Este constituye la tercera estrategia.

La tercera estrategia se manifiesta como actos contraculturales en la forma de interferencias alegóricas, como imágenes o metáforas, que "tienen lugar saliéndose del libreto que la intelligentzia pedagógica ha marcado para el docente" (Medina, 2006, p. 41, destacados del propio autor). A nivel de las relaciones conceptuales, deberíamos asimismo incluir, como cuarta estrategia en el esfuerzo de lucha contra la fragmentación, el esfuerzo de articulación constante, de recomposición o de reintegración, que es una estrategia de resistencia cuando lo sostiene una lógica emancipadora. 


\section{EL POSICIONAMIENTO PEDAGÓGICO DE LETELIER EN EL CONTEXTO MODERNIZADOR CHILENO}

Nos acercaremos a un momento particular de ese diálogo, producido lejos aún de la entronización de las categorías de la psicología educacional hegemónica durante el siglo XX, por lo cual tiene licencias epistemológicas a las que es preciso atender para desarrollar un ejercicio metateórico que permita comprender mejor las restricciones del delineamiento actual del acto didáctico. Desde una concepción culturalista y humanista del acto didáctico como la que hemos definido, vamos a adentrarnos en el pensamiento de Valentín Letelier quien, como Hostos o Martí, entre otros, escribe en pleno proceso de lo que Rama llama "el período de la modernización latinoamericana” (Rama, 1984), acercándose al positivismo comteano y spenceriano, a los cuales no deja, sin embargo, ayunos de crítica. Desde allí, nos interesa mostrar el posicionamiento de Letelier como intelectual preocupado por la construcción de lo nacional vis a vis de un pensamiento pedagógico comprensivo. En su obra, se destaca un proyecto pedagógico emancipador que asume el principio de sinonimia entre educación y gobierno, al mismo tiempo que hace una cuidadosa reinscripción del proyecto didáctico indagativo spenceriano; todo ello para dar forma, finalmente, a lo que llamaremos una pedagogía del desarrollo que logra articular el proceso pedagógico más allá de los lindes actualmente hegemónicos determinados por las ideas de aprendizaje y de escolaridad.

Valentín Letelier nace en la ciudad de Linares, en 1852. Hijo de un agricultor cuya estabilidad financiera se vio progresivamente mermada, tuvo una difícil primera educación, la que pudo llevar a buen término en Talca, gracias a familiares, y luego en la capital del país, gracias a sus destacados logros, en el Instituto Nacional dirigido a la sazón por Barrros Arana (Galdames, 1937, p. 17). En 1872 ingresa a la carrera de leyes en la Universidad de Chile, estudios que costea trabajando como profesor suplente en el Instituto. Dos años después forma parte del Círculo Positivista, dirigido desde 1870 por José Victorino Lastarria. En 1875, ya egresado, parte al norte del país, a Copiapó, a desempeñarse como profesor de literatura en el Liceo de esa ciudad, donde funda una Academia Literaria. Permanece allí tres años, al término de los cuales vuelve a Santiago. Los departamentos de Copiapó y Caldera lo proclaman diputado, iniciando de ese modo su vida parlamentaria. En enero de 1882, se traslada a Alemania como secretario de la Legación en Berlín. Allí pasará casi cuatro años en los que conocerá las experiencias pedagógicas más destacadas de la época.

A su regreso desarrolla una fuerte actividad educacional en el país. Se compromete en la creación del Instituto Pedagójico, ${ }^{10}$ establecido en 1889, el que hasta $1981^{11}$ será la principal institución chilena de formación docente. Además,

10 Según la ortografía de la época.

11 La dictadura militar de Augusto Pinochet separó al Instituto Pedagógico de la Universidad de Chile, convirtiéndolo primero en la Academia Superior de Ciencias Pedagógicas y, luego, en la actual Universidad Metropolitana de Ciencias de la Educación. 
redacta un Plan de Estudios Secundario, solicitado al Consejo Universitario por el gobierno, elabora también el plan de estudios de Ciencias Legales de la Facultad de Derecho y publica, con Julio Bañados y el intelectual puertorriqueño Eugenio María de Hostos, un libro que contiene textos escritos entre 1880 y 1889 sobre la reforma a la enseñanza del derecho. Por si fuera poco, en 1888 redacta el programa del Partido Radical y retoma su labor parlamentaria como diputado por Talca hasta la disolución del Congreso en 1891 por causa de la Guerra Civil. ${ }^{12}$ Ese año, en enero, firma la declaración del Congreso que destituye al presidente Balmaceda. En marzo es apresado y relegado a Iquique hasta que, en Septiembre, tras triunfar el bando congresista, es liberado. Es elegido, y luego reelegido, rector de la Universidad de Chile, cargo que ocupa entre 1906 y 1913, y que abandona para ocupar el de fiscal de la Corte de Cuentas, declarado incompatible con el rectorado gracias, según Galdames, a oficios de sus detractores que dejaron en su espíritu una sensación de acritud (Galdames, 1937, p. 252). Continúa publicando textos sobre materias legales hasta su muerte en 1919.

Las coordenadas sociohistóricas de su discurso pedagógico, en un sentido amplio, parten a mediados de la década de 1870 con su adscripción al Círculo Positivista en 1874 y con el comienzo de su labor docente en Copiapó, en 1875. En un sentido más estricto, hay que atender a la década de 1780 y los primeros años de la siguiente, cuyos límites son determinados por la escritura de los artículos que forman parte de La lucha por la cultura, publicado en 1895, y la de su Filosofía de la educación, producida a lo largo del significativo año 1891 y publicada al año siguiente. Los eventos históricos de este período escritural circunscriben su visión democratizadora y antimperialista de la dimensión política de lo pedagógico, dentro de los cuales participa desde su experiencia como diputado de la República y desde su rol como forjador del Instituto Pedagójico en 1889. Su repercusión en Chile es indudable a través de las instituciones que contribuyó a fundar; u pensamiento influyó en otros intelectuales chilenos importantes como Darío Salas y el presidente de Chile don Pedro Aguirre Cerda. A nivel latinoamericano sus ideas hallaron eco en Hostos; pero ciertamente no ha tenido la presencia que merece, aun cuando fue tempranamente publicado en Argentina por Cabaut y Cía. En Chile, Letelier fue

12 El conflicto se origina por el rechazo de parte del Legislativo al presupuesto de la nación presentado por el Ejecutivo y la decisión de este último de hacer valer el del año anterior, ante lo cual sus miembros responden alzándose con la marina y firmando la destitución del Presidente, a quien acusan de despilfarro y de ejercer una dictadura. El Presidente, a su vez, disuelve el Congreso. Mientras el ejército se divide entre ambos bandos, la armada apoya únicamente a los congresistas en un conflicto que acabó con la dimisión del presidente en el mes de agosto. La historiografía tradicional ha enfatizado la dimensión política del conflicto; las perspectivas ligadas al marxismo enfatizaron el aspecto económico (Pizarro, 1971; Ramírez Necochea, 1972). Recientemente se ha puesto la mirada en la multidimensionalidad del proceso. Para Subercaseaux, en cambio, se trata de una Guerra Civil "puesto que fue un enfrentamiento que involucró (directa o indirectamente) a todo el tejido social en sus más diversas tramas y que por lo mismo tuvo consecuencias de orden político, económico, social y cultural” (Subercaseaux, 1988, p. 22). 
materia de estudio principalmente desde la filosofía ${ }^{13}$ y el derecho de manera recurrente hasta mediados del siglo XX. Últimamente, su figura está siendo rescatada desde los estudios culturales. ${ }^{14}$ La deuda con su obra persiste, sin embargo, en el campo pedagógico.

En la perspectiva crítica que adopta Letelier sobre los asuntos pedagógicos, dentro de ese contexto modernizador, resultan cruciales dos sucesos: por un lado, la guerra civil de 1891, esa "metáfora de un tiempo mucho más extenso que el momento original" (Subercaseaux, 1988, p. 27), en la que fue activo, tardíamente arrepentido, participante en la destitución del presidente, y al calor de la cual escribe su Filosofía de la educación (1891). Por otro lado, el incidente Baltimore ${ }^{15}$ fue, según Letelier, "de lo mas ${ }^{16}$ mortificante que cabe para el patriotismo. Los términos en que Chile imploró el perdon de los Estados Unidos i les manifestó que se arrepentía de haber obrado con dignidad, avergonzarán eternamente a todo hombre en cuyas venas corra sangre de la raza chilena" (Letelier, 1895, p. 92). Ambos sucesos propician que el acto didáctico, modelo o escena matriz del vínculo formativo que constituye el proceso educacional, se configure en sus escritos como una experiencia indagativa emancipadora que guía un proyecto formativo democratizador de la nación, "hermanando" a sus miembros (Letelier, 1927, p. 165). Esta concepción es una contestación a un contexto marcado por, a lo menos, dos relaciones de subordinación: en lo internacional, la del militarismo norteamericano; en lo nacional, la de las ideas liberales bajo la Coalición liberal-conservadora de gobierno que sucede a Balmaceda.

El positivismo, en este contexto, es asumido críticamente por Letelier respecto de los tintes conservadores que le imprimiera el pensamiento de Comte y de Bain. Desde esta plataforma, emprende una reconstrucción científica del campo educativo levantando como primera prioridad la construcción de una pedagogía que soporte ese proyecto modernizador y democratizador que encarna, concretamente, en la creación del Instituto Pedagógico. Su empresa discursiva en la filosofía de la educación es la de construir una pedagogía desde la especificidad del

13 Allí, fue principalmente Roberto Munizaga quien se preocupó de sus obras.

14 Ver, por ejemplo, los trabajos de Juan Carlos Skewes (1999) "Valentín Letelier, el multiculturalismo y el nuevo pluralismo legal en antropología" en Revista Derecho y Humanidades (n. 7, p. 235-242, 1999); de Bernardo Subercaseaux (1988). Y el de Grínor Rojo, El campo cultural latinoamericano de la primera modernidad: 1870-1920, próximo a publicarse. La reciente compilación de María José López y José Santos Herceg, Escritos republicanos: selección de escritos politicos del siglo XIX, publicada en Santiago por LOM Ediciones, 2011, contribuye a la circulación actual de su pensamiento.

15 En octubre de 1891, marinos norteamericanos pertenecientes al navío "Baltimore" se vieron involucrados en una gresca vulgar en una cantina de Valparaíso. Como fruto de la investigación ordenada al capitán del navío, Estados Unidos declaró que la pelea había sido un ataque premeditado que representaba un acto hostil contra ese país. Los resultados de la investigación judicial chilena, que confirmaban el carácter vulgar y no político del incidente, no alteraron esta impresión norteamericana, con lo cual el conflicto escaló sus proporciones. Chile recibió un ultimátum exigiendo un retracto y amenazando con una intervención bélica. Chile debió cambiar su postura y aceptar, además, el pago de indemnizaciones a las familias de los fallecidos.

16 Transcribo fielmente según la ortografía vigente en la época de la edición citada. 
hecho pedagógico como fenómeno complejo: "una cosa es saber, otra saber enseñar, i otra saber enseñar el arte de enseñar”(Letelier,1895, p. 416). El objeto de preocupación de Letelier no se agota en los lindes del racionalismo académico spenceriano que se conformaba con el saber de las disciplinas como plataforma principal de trabajo Letelier, sino que, por el contrario, avanza hacia una comprensión, decimos, de la especificidad humana del fenómeno pedagógico:

En Chile es creencia jeneral que cualquier injeniero puede hacer un buen profesor de matemáticas, que todo médico es competente para enseñar las ciencias naturales, i que la enseñanza de las humanidades se pone en buenas manos cuando se la encomienda a los abogados. Es éste un gravísimo error, porque lo mas propio para aquilatar la idoneidad de un profesor no es su saber, es su didáctica. Mui a menudo grandes sabios han escollado en la enseñanza por falta de preparacion pedagójica, i no hai inconveniente para que el mas renombrado literato quede en ridículo al dar la primera leccion de retórica. Si es verdad que no puede ser gran profesor el que no posee mucha ciencia, ello es que pierde menos el que disminuye sus conocimientos que el que desmejora sus métodos. (idem, p. 366)

Es significativo que Letelier matice el cientificismo con que él quiere caracterizar a la pedagogía haciendo parte a la cultura del campo de su reflexión sobre la pedagogía. Para él:

la pedagojía es ciencia i es arte [...] es un patrimonio universal que todas las naciones pueden disfrutar. No desconozco yo que la idiosincracia de cada pueblo impone la necesidad de procedimientos especiales para educarlo; i me consta que algunas formas didácticas que rinden excelentes frutos en las escuelas alemanas no se acomodan a la índole de los chilenos. (idem, p. 442)

Su definición avanza así hacia una comprensión del sentido humano general al mismo tiempo que de la especificidad cultural del fenómeno pedagógico, si bien contrapesada por cierto darwinismo social (Letelier, 1927, p. 42).

Desde esta idea de la pedagogía como un "patrimonio universal" de todas las naciones, se producen dos ampliaciones categoriales relevantes que llevan lo pedagógico más alá del aula y más allá de la escuela. Para el ex rector, es:

incompleta aquella teoría que la pedagogía clásica vulgarizó, según la cual no hay más educación que la que se da o se recibe en la escuela. Cuando se la entiende en este sentido estricto, no alcanza la educación a explicar todo el ser bumano porque muchas de las peculiaridades que distinguen al adulto han sido determinadas por influencias puramente físicas o sociales sin la intervención de las influencias escolares. Por el contrario, en el sentido complejo que la corresponde, la educación comprende toda influencia que para su bien o para su mal se ejerce sobre una persona por medio del ejemplo o de la enseñanza, de la pena o del premio, del placer o del dolor, de la amenaza o de la esperanza, de la persuasión o de la fuerza. (idem, p. 39, destacado es nuestro) 
Es notable su conciencia de la reintegración teórica que implica la incorporación del ámbito del desarrollo humano a la experiencia escolar entendida como proceso formativo latu sensu, ${ }^{17}$ al concebir la pedagogía en una dirección humanizante ampliando lo educativo y logrando una función interpretativa, no solo prescriptiva, de la teoría. Articula, de este modo, dos tipos de educación: la sistemática y la espontánea o la escolar y la doméstica, desescolarizando, de paso, la labor analítica de la pedagogía.

En la misma dirección de lo ya dicho, encuentra una actividad formativa en la vida de instituciones que no se había reconocido explícitamente hasta ese momento, conceptualizada en la noción de "formas educativas". Mediante esta noción, Letelier visibiliza al interior de la teorización pedagógica formal la relación entre las formas educativas y el ejercicio de la coerción al interior del acto didáctico. Bajo esta categoría, agrupa prácticas diversas que integran la educación física, el horario, el régimen escolar, las vacaciones, el régimen disciplinario, el internado, la evaluación, las excursiones y las lecciones de cosas.

Esta nueva ampliación categorial introduce en lo didáctico la exterioridad del aula: "llamo formas educativas a los modos y medios que las autoridades educadoras emplean para modelar el ser de los educandos" (idem, p. 51). Esta categoría, hermenéutica más que prescriptiva, cultural más que técnica, nos ayuda a ver el alcance que cobra el acto didáctico: una pedagogía del desarrollo donde toda la sociedad y la vida institucional, y no solo la escuela, es un aula. La funesta división introducida por Comenio entre obrar y aprender se sutura reconciliando el espacio escolar y extraescolar en la recuperación, para ambos, de la idea de "obrar”; de ahí la función reintegradora de la definición de educación: toda educación debe preparar para la vida. No solo se limita a proponer la continuidad de ambos tipos de educación, que lo ubican como uno de los primeros en esbozar la noción de educación continua, sino que levanta una noción de lo educacional que incluye dimensiones diversas: la intelectual, la social, la moral, la estética, como es visible en su análisis de las excursiones y las lecciones de cosas.

\section{PROYECTO PEDAGÓGICO Y PROYECTO DIDÁCTICO PARA LA EMANCIPACIÓN}

Reconociendo, entonces, el carácter de patrimonio universal de la pedagogía, a Letelier le interesa también la especificidad cultural de su discurso, lo cual lo compromete en un proyecto de nación. Letelier tiene convicción en la necesidad de elaborar una pedagogía nacional, tarea del Instituto Pedagógico que requiere en primer lugar la recurrencia a todas las ayudas posibles debido a lo que él percibe

17 "Por causa de la atención casi exclusiva que en las escuelas públicas se prestó siempre a la acción docente con desmedro de la acción educativa, la pedagogía ha desarrollado mucho más la teoría de la enseñanza que la de la educación, y dejándose absorber completamente por el estudio especial de las formas didácticas, ha descuidado de manera lamentable el estudio genérico de las formas educativas. Pero si esta tendencia unilateral explica la omisión, no la justifica porque la teoría de las formas didácticas queda trunca y en muchos puntos oscura sin la de las formas educativas"(Letelier, 1927, p. 51). 
como "menor cultura" y "debilidad" de la nación. Es lo que uno puede deducir de la defensa que hace del Instituto Pedagógico contra sus detractores: "para todos los chilenos, defender el Instituto Pedagójico es defender uno de los ajentes mas poderosos de la cultura nacional, i suprimirlo es imposibilitar la formacion del profesorado chileno, es hacernos perpetuos tributarios de la pedagojía estranjera" (Letelier, 1895, p. 419). Letelier no pierde de vista, aun sumido en tales supuestos, que el destino es la construcción de una pedagogía particular que debe surgir de una reelaboración acuciosa del saber producido por sus contemporáneos europeos, y la lleva a cabo anotando cada vez que corresponde las cuentas que han de cobrarse, sea a Spencer, sea a Comte o a otro. Adelantándose a Vasconcelos, e incurriendo en la misma desconsideración de los indígenas, vincula esa labor de síntesis con la condición mestiza de los latinoamericanos:

Todos los hombres que nos traigan algun continjente de intelijencia, de industria, de arte, de ciencia,o de simple fuerza muscular, son bienvenidos. A ninguno preguntamos de dónde viene, a dónde va, quienes fueron sus projenitores, ni a que raza o relijion pertenece. Pedimos a cada nacion lo mejor que tiene, i aceptamos la ayuda de parte de quien quiera prestárnosla. En cuanto a las rivalidades de raza, nosotros no las conocemos, i casi no las comprendemos: los americanos nos preciamos de ser hijos de todas las razas. (idem, p. 440)

Dentro de su plan de construcción de la nación, un primer pilar es el de la población chilena en su totalidad, donde busca ligar a los individuos mediante una "instrucción general" que persigue la problemática utopía positivista de "restablecer constantemente la perfecta uniformidad de todos los espíritus". En torno a ello, el Estado es fundamental como "un reducto inespugnable que nos permita conservar a la educacion pública su nobilísimo carácter de educacion nacional, sin tendencias oligárquicas, sin distinciones sectarias, sin propósitos de lucro" (idem, p. 150). La educación pública democratiza mediante el reconocimiento del mérito, lo que "permite a la sociedad aprovechar los talentos que nacen en las últimas clases" (idem, p. 168). El proceso formativo así, es más rico aún en las sociedades libres, pues "el hombre aprende como ciudadano muchas cosas en que ni aún se le ocurre pensar como siervo" (Letelier, 1927, p. 61). Este desencaje antioligárquico lo previene ante el conservadurismo de Comte, quien en el Curso de filosofía positiva, atemperado ya el calor de los acontecimientos de 1848 en Europa, había propuesto la tesis de la homogeneización mental pensando en el positivismo como educación únicamente para las masas, sin pretender alterar la vigente posesión del poder sino, más bien, consolidarla ${ }^{18}$ para sus posesores (Comte, 1984, p. 166). Este solo dato del pensamiento

18 "Desde que los gobiernos han renunciado esencialmente, aunque de una manera implícita, a toda seria restauración del pasado, y los pueblos a todo grave trastorno de las instituciones, la nueva filosofía ya no tiene que pedir a ambas partes sino las disposiciones habituales que, en el fondo, se está dispuesto por doquier a concederle [...] o sea, libertad y atención. En estas condiciones naturales, la escuela positiva tiende, de un lado, a consolidar todos los poderes actuales en sus posesores, cualesquiera que sean, y, 
comteano por sí solo resultaba, a mi juicio, atractivo para las élites oligárquicas latinoamericanas.

En Letelier la educación y el educando son prefiguraciones de la sociedad y el ciudadano que garantizan la construcción de la nación futura. En ello reside el valor emancipador del conocimiento, convencimiento desde el que levanta su proyecto pedagógico:

proponemos como base del sistema de enseñanza pública la ciencia pura, la ciencia que no profesa ni despierta odios, la ciencia sin hipótesis no comprobadas que alarman a muchas conciencias, la ciencia sin latines ni sectarismo que cinchan el cerebro i traban el libre vuelo del espíritu humano. (Letelier, 1895, p. 313)

Esto tiene una relación difícil con su adhesión a una comprensión progresiva de la historia que sitúa su proyecto bajo los deslindes de la oposición civilizaciónbarbarie, pues lo racional produce el distingo entre lo "atrasado" y lo "antiguo" con lo "civilizado". El riesgo de elitización de su propuesta pende así de un delgado lazo moral que sustenta el pacto social: el cumplimiento de un deber impuesto por la naturaleza gregaria del hombre, pues "la sociedad misma se disolvería si el anhelo del bien no mantuviera permanentemente unidos a todos sus miembros".

$\mathrm{El}$ maestro cumple el proyecto didáctico, que completa en el aula el proyecto pedagógico mayor, llevando al educando a "habituarse a la autoeducación esto es, a estudiar, a observar, a explicarse las cosas por sí mismo, a perfeccionarse, a instruirse y adaptarse sin ayuda ajena y cada día mejor a las condiciones naturales y sociales" (Letelier, 1927, p. 38). Esto reinscribe el proyecto didáctico de Spencer, a saber, "formar un agente eficaz para la investigación, para el pensamiento independiente y para el descubrimiento" (Spencer, 1912, p. 86), aunque resulta postergado mediante una concreción centrada en lo instructivo (idem, p. 104) y de una forma expositiva que solo entrega "conceptos que preparan para todo esto". Letelier (1927, p. 503-504) cumple con el horizonte spenceriano de ese proyecto didáctico: "gobernarse y discurrir sin una ayuda extraña" implica una preparación para la vida, anclada, pero no circunscrita, al radio de las disciplinas. Esa preparación debe actuar como arma "contra la contingencia y las sorpresas del mundo".

La interferencia alegórica en que se sintetiza el proyecto, usada repetidas veces, es la de dotar de alas al educando:

el educador científico pone alas a sus discípulos y les da larga para que salgan a recorrer el mundo sin acordarse más de él. El educador eclesiástico, desconfiando de la libertad, trata al contrario, de someterlos a su férula para toda la vida. (Letelier, 1927, p. 505)

El ribete político de este proyecto viene dado por otra metáfora de la autonomía del sujeto: gobernarse (idem, p. 508) que, si bien no es una interferencia

por otra parte, a imponerles obligaciones morales cada vez más conformes a las verdaderas obligaciones de los pueblos" (Comte, 1984, p. 166). 
alegórica en cuanto que su presencia tiene origen en los autores europeos (Bain, 1882, p. 107; Spencer, 1912, p. 139), sufre sí una reinscripción al ser llevada al terreno de la emancipación y autogobierno y no al del gobierno heterónomo de los educandos. Letelier (1895, p. 44) llega a la idea, y lo dice mucho antes que Aguirre Cerda, en septiembre de 1888, de que "para el sociólogo y para el filósofo, [...] bajo el respecto moral, gobernar es educar".

Letelier (1927, p. 30) legitima la autodeterminación del propio educando y clausura la asimetría de la relación pedagógica propia del acto didáctico canónico:

Si el espíritu del hombre no es una simple aptitud dispuesta a recibir en cada momento la impresión de las influencias externas, si es una entidad activa dotada de facultades propias, respetar su personalidad y secundar sus fines es el primer deber de todo sistema educativo.

Esta idea invierte la relación canónica donde el educando sigue al maestro que le señala el rumbo, y es preciso detenerse un momento, siquiera mínimamente, en el valor que esta idea pueda tener en un contexto dominado por las ideas pestalozzianas, impregnadas del deseo; en palabras del propio Pestalozzi (1801, p. 193), de mecanizar la educación y "elevar a necesidad física los resultados de toda instrucción en esas tres materias". Para Letelier (1895, p. 356), en cambio, debido a una plasticidad espiritual limitada que impide al docente una manipulación ad libitum del proceso formativo, se asume la opción contraria, la de secundar al educando:

nunca es propio de seres racionales obrar sin discernimiento i dejarse arrastrar pasivamente por la corriente general. Como ajente moral, el primero de los deberes del hombre es el de elegir por sí mismo el camino que debe seguir, las obras a que debe contribuir, las tareas en que debe cooperar.

El niño froebeliano en el que está pensando Letelier (1927, p. 511), versión infantil del "sabio que investiga" y que, como aquél, usa la vía inductiva, se halla cruzado por la oposición civilización-barbarie. Aunque desestima el criterio racial para establecer diferencias entre los pueblos y los sujetos, por ser un criterio metafísico, Letelier reinstala lo básico de la oposición que la misma permite mediante el criterio de la capacidad racional. Las diferenciaciones culturales que había logrado suprimir reaparecen en un acto supresor de las diferencias que asume con entusiasmo, desde la tesis positivista de la crisis derivada de la heterogeneidad. Esto lo lleva a asumir una estructura de actitud y referencia colonial frente a los pueblos indígenas contra cuya figura recorta la del educando.

Éste se construye frente a una doble antifigura. Por una parte, frente al "salvaje", un Otro radical del educando presentado como suerte de grado cero de "la historia del espíritu". Su definición no es ontológica sino social: es el resultado de las "influencias sociales", como en los fueguinos, y no del factor biológico. Por otra parte, lo hace frente a la figura del Anormal, la que entra a formar parte de los discursos de la pedagogía, según un criterio de capacidad racional. En el caso de Letelier esta segunda categoría hace referencia al pueblo mapuche. El ex rector 
participa de un consenso nacional que invisibilizó las "culturas étnicas (mapuche y quechua-aymara) y campesina, ámbitos que si bien existieron, vivían a fin de siglo soterrados y marginados del mapa de la cultura nacional" (Subercaseaux, 1988, p. 242). Letelier (1927, p. 602) los ubica en el grupo de los retardados y aconseja adscribirlos a cursos inferiores donde "no se exponen a la vergüenza de nuevos fracasos". Lo anormal es simple y llanamente la negación de lo normal en una inespecífica "generalidad" urbana y metropolitana. Apuntando a un sentido integral, pero que privilegia lo racional, el desarrollo como "desenvolvimiento" es puesto sobre el terreno didáctico (idem, p. 171) en relación de correspondencia con el horizonte de aprendizaje a partir del libre despliegue de la actividad intelectual del educando sobre el mundo. Su desafío pedagógico es el de llevar adelante un proceso didáctico que aborde simultáneamente ambos procesos, de aprendizaje y de desarrollo:

Según lo he observado una y otra vez, en los pasados siglos no se curaban los maestros de adoptar formas didácticas que tuviesen eficacia educativa; trataban el espíritu del educando como si fuese una aptitud meramente receptiva, no como verdadera facultad activa; y concretándose a repletarlo de nociones, no lo fortalecían, ni lo desarrollaban, ni lo educaban y en tanto cuanto prescindían de la asimilación intelectual, ni aun lo instruían. Contra este vicio capital de las antiguas formas didácticas, ha reaccionado vigorosamente la pedagogía científica educando al maestro en doctrinas que le imponen la obligación de dar siempre a la enseñanza, con el auxilio de la intuición, finalidad educativa. (idem, p. 575)

El aprendizaje válido es el de carácter científico, por medio del cual el conocimiento es producido por el propio educando de manera inductiva (idem, p. 512-513). Lo aprendido implica desarrollo en la medida en que sea coherente con el nivel en que se sitúe respecto de la maduración del educando; por ello el aprendizaje se identifica más bien con el "ejercicio de la razón”. La palabra "ejercicio" en Letelier (1895, p. 254) tiene un sentido muy claro de intervención en un mundo extraescolar, como se colige de sus referencias al ejercicio de una carrera, al de la libertad (idem, p. 136), al ejercicio de las funciones de un cargo, ${ }^{19}$ etc.; como al mundo escolar cuando el "ejercicio" se traduce en el funcionamiento de aquellas cualidades del sujeto que quieran activarse para lograr su desarrollo, trátese de lo manual (idem, p. 293), lo artístico (idem, p. 295), etc.

El marco regulatorio de la actividad del educando es el método experimental (Letelier, 1927, p. 507), apropiado al nivel del desarrollo del sujeto a condición de que éste se halle "insaciable de saber". En esa legalidad científica, el sujeto o está expuesto al "peligro de errar" (idem, p. 506) o simplemente no desarrolla el espíritu y se queda en los marcos de una pedagogía conservadora en oposición a la cual "la enseñanza científica observa que errar no es pecar; descubre ante la mirada de los educandos la perspectiva de la naturaleza infinita y los empuja a la exploración de

19 Letelier (1895, p. 203, 210, 218, 220). 
la verdad" (idem, p. 507). La posibilidad del error como cláusula relevante del contrato didáctico es la contracara del derecho a tener y perseguir fines propios, cláusula que había sido desterrada explícitamente de la pedagogía lasalleana mediante el recurso de ignorar la ocurrencia del error y buscar la del acierto de niño en niño (La Salle, s.f., p. 49). El demonio del error, introducido no sin grandes cuidados en la pedagogía rousseauniana, había sido llanamente descartado de la teorización pestalozziana debido al temor del suizo por la caoticidad de lo real (Pestalozzi, 1800, p. 25) que funda un afán mecanizador de la educación (idem, p. 38).

El docente de Letelier (1895) es un mediador dialógico que permite al educando ingresar en una comunidad intelectual prestándole su propia reflexión, sus interrogaciones, para ponerlo en situación de interlocutor reflexivo atento a:

la forma de las interrogaciones, el jiro de los diálogos, la esposicion del asunto, el manejo de los instrumentos, el arte de interesarles la atención de los alumnos, los resortes que se deben tocar para hacerles tomar parte activa en el estudio. (idem, p. 367)

Se ofrece como puente en medio del hiato entre el educando y la ciencia, toca "los resortes" del educando que permiten aprovechar la "insaciable curiosidad que anima al niño en aquellos primeros años de su vida en que su inteligencia viene abriendo los ojos a la contemplación del mundo"(Letelier, 1927, p.513). La relación dialógica con el educando, montada sobre experiencias de contacto con objetos ${ }^{20}$ de la realidad, aparece ocupando un lugar de privilegio entre las premisas, toda vez que "la enseñanza por excelencia es la enseñanza oral e intuitiva" (idem, p. 566).

El docente ayuda dialógicamente al educando a tomar conciencia del proceso observacional que su naturaleza curiosa lo impulsa a realizar, para perfeccionar desde allí su capacidad de abstracción:

llamar la atención a la repetición de los hechos, a la regularidad de los fenómenos, a las propiedades de las cosas, a sus semejanzas, a sus diferencias, para ascender por medio de la razón a las generalizaciones, es el único procedimiento conforme con el desarrollo espontáneo de la inteligencia. (idem, p. 513)

Esta práctica es paralela a la de "estimular el espíritu de duda" y que consta de la provocación intencionada ("artificial", dice él) por parte del docente para conseguir la formulación de objeciones por parte del educando (idem, p. 582). Maestro y educando entran en íntima relación con el ejercicio intelectual propio de la ciencia. Este proceso didáctico, puente entre el mundo de la ciencia y el mundo del niño, se orienta desde el aprendizaje y la instrucción al desarrollo en general y al desarrollo de la inteligencia en particular (idem, p. 574).

20 El libro de texto para Letelier es un instrumento supletorio para los casos en que no sea posible la "enseñanza objetiva". La enseñanza oral "afianzada siempre que proceda por los medios objetivos, debe prevalecer en general contra los textos” (Letelier, 1927, p. 567). 


\section{CONCLUSIONES}

A la luz de lo expuesto, las ideas de Letelier aparecen recuperables, pedagógicamente, para una perspectiva de crítica metateórica en torno del concepto de acto didáctico por constituir un modo de romper tales continuidades metateóricas. La clave crítica de lectura que permiten los aportes de Fanon, Said, Gramsci y Medina, tanto en la clarificación de una dirección distintiva de la lucha emancipatoria como a propósito de sus estrategias, contribuye a visibilizar la originalidad del pensamiento de Letelier en relación con el discurso metropolitano y su pertenencia a una tradición intelectual latinoamericana de vocación crítica. El incidente Baltimore y la Guerra Civil de 1891 contextualizan su ejercicio intelectual y levantan la emancipación como un sello de su propuesta, que lo previene activamente contra el sentido conservador del acto didáctico canónico en tanto matriz de distribución "de una cierta conciencia geopolítica" (Said, 2001, p. 31-32), situando la cultura y el Estado como espacio estratégico y de lucha (Subercaseaux, 1988, p. 140-141).

Es preciso, en todo caso, considerar que en su discurso los elementos progresistas y críticos, derivados de su posicionamiento frente a los hechos históricos de 1891 que anima la escritura de su Filosofía de la educación, coexisten con otros de carácter conservador, insertos en el darwinismo social y el racialismo, o la "utilización de la raza como una categoría científica válida, con cuya mediación se cree que es posible dar cuenta de la verdad de ese otro [...] encubierta, para el afianzamiento del poder"(Rojo,2011, p. 27), circulantes en su época. Estas coexistencias en Letelier, antioligárquico y democratizador, hijo de un agricultor empobrecido (Galdames, 1937), dan cuenta de un diálogo, situado en coordenadas históricas concretas, entre su pensamiento y el pensamiento europeo de su época, que es crítico en muchos aspectos y es más bien tributario en otros.

En lo político, el fomento de la libertad decisional revierte la construcción del alumno como sujeto de la carencia, siempre lejano y subordinado a la figura subjetivamente plena del maestro, y se dirige más bien hacia la construcción de un sujeto cuyo ejercicio presente en el espacio de aula es análogo al del adulto en el espacio extra-aula. El sello del pensamiento liberal es notorio en el énfasis de esta figura como individualidad, con lo cual hay también una restricción del ingreso de lo político en el aula, al negar el estatus de colectividad a los sujetos en ella.

En cuanto a la separación entre el aula y la vida, las lecciones de cosas, como "formas educativas" y "formas didácticas", son cruciales por ser el prototipo de "la pauta que se debe seguir invariablemente en todas las ramas de la enseñanza" (Letelier, 1927, p. 513). Su carácter adidáctico tiene como eje central la actividad de observación y reflexión que constituirían el "estudio" como trabajo específico del educando y que es el proceso mismo por medio del cual la ciencia se desarrolla (idem, p. 514). La apertura que esto significa es evidente cuando lo comparamos con el terror de Bain a la distracción y al placer de los educandos, que lo lleva a sugerir que las ventanas de las aula queden fuera de la vista de los niños (Bain, 1882, p.40). Letelier estructura el entorno didáctico mediante un doble principio mimético que relativiza la autonomía del aula: en lo racional, "lo natural es que para dar a 
conocer las ciencias, siga los mismos procedimientos que la investigación sigue para formarlas"(Good, 1960, p. 510). Al igual que el Freire de las Cartas a quien pretende enseñar, Letelier está dotando de un sentido específico al "estudio" bajo esa premisa mimética, dándole un sentido humano que, finalmente, es también político. Para Freire (1994, p. 31,36), estudiar es un quehacer crítico de comprensión de "objetos" que se deben poner en relación con otros.

En Letelier, estudiar -como actividad distintiva del educando- e investigar -como distintiva del sabio- resultan, como en Freire, trabajos análogos de comprensión de objetos. Ambas actividades, del educando y del sabio, adoptan la forma de entornos con situaciones que tienden a una autenticidad intelectual como en las lecciones de cosas o las excursiones. En ambos espacios, el áulico y el investigativo, "la verdadera vida del pensamiento solo se desarrolla en la libertad", lo cual explica la premisa de que el maestro deba "secundar" los fines del educando, cuya libertad de pensamiento puede parecerse a unas "expansiones indisciplinadas de la razón" (Letelier, 1927, p.523). El espacio de aula y el mundo exterior se hallan coordinados mediante dos premisas miméticas: a nivel pedagógico, practicar el ejercicio de la libertad como cualidad del ciudadano; a nivel didáctico, asumir la legalidad científica como norma tanto en el modelamiento de las situaciones didácticas, de diálogo con el maestro, como de las adidácticas, donde el educador sale de escena para permitir las expansiones indagativas del educando.

El corolario de esto es imprescindible para una pedagogía emancipatoria, pues se trata de una prevención temprana contra el autoritarismo que habla bien de un modo simétrico de relación entre los sujetos participantes del hecho educativo, muy lejano del "terror saludable" (Bain, 1882, p. 82) de los educandos hacia el maestro y de la proscripción de la imaginación (idem, p. 132) y del placer (idem, p. 35) que preconizaba su contemporáneo, Alexander Bain. El poder decisional basado en la facultad intelectual que se reconoce como un derecho del educando a tener sus "propios fines" (Letelier, 1927, p. 30) es la raíz que cimenta tal simetría, razón de ser de la independencia de un sujeto frente a otro:

no está bien educado ni el que solo cumple su deber por respeto a la autoridad, ni el que no se siente capaz de emanciparse de ella para proceder por sí mismo. Para preparar la emancipación de los educandos, el maestro ni debe defender con mucho calor los fueros de su autoridad ni creer que es motivo de mucha irritación la rebeldía [...] un educando que siempre obedece sin formular jamás una protesta, ni una observación, concluye por habituarse a la sumisión y la dependencia. (Letelier, 1927, p. 62)

En este sentido, su propuesta pedagógica se acerca a lo que podríamos denominar como una pedagogía y una didáctica del desarrollo, tareas aun inconclusas y dentro de las cuales cabe tenerlo como referente. Letelier acomoda su propuesta en los lindes del racionalismo académico (Romeo, 1998), pero vertebrando el proceso formativo sobre la base del ejercicio de la capacidad decisional del sujeto, clausurando la asimetría de la relación pedagógica al tiempo que el educador se pone al servicio de las exploraciones intelectuales del educando y tolera cuotas saludables de rebeldía. 
Apuntemos los ámbitos en que su pensamiento muestra una vigencia considerable hasta hoy. Primero, en cuanto amplía la configuración posible del acto didáctico más allá de la tríada didáctica sustentada en la autonomía del espacio escolar frente al de la vida, la que permitía a Chevallard (2009, p. 42) ver los conflictos y soluciones en la noosfera, respectivamente, como patologías y como manipulación "terapéutica" del saber. En este punto, Letelier ayuda a entender esta categoría teórica como la articulación de una propuesta pedagógica tendiente a la construcción de lo social, donde participan sujetos no solo en términos de intelectos sino de ciudadanos. Este vuelco, posibilitado por la emergencia de categorías como la de "formas educativas", propone una complejización de la comprensión del proceso formativo $^{21}$ que, junto a la ampliación del rol del educando mediante los de investigador y ciudadano, muestra el camino de salida a una configuración del acto didáctico presente en las formulaciones triádicas del consenso teórico actual que acepta como natural su escolaridad. La categoría de acto didáctico se enriquece, así, cuando reconocemos en ella la necesidad de albergar otras que den cuenta de aspectos como los evidenciados en la reflexión de Letelier, como las de roles, proyecto pedagógico, proyecto didáctico, legalidad didáctica, entorno, entre otras.

El camino de Letelier es el de la defensa de la educación pública y el reclamo del Estado como "un reducto inespugnable que nos permita conservar a la educacion pública su nobilísimo carácter de educacion nacional, sin tendencias oligárquicas, sin distinciones sectarias, sin propósitos de lucro"(Letelier, 1895, p. 150). La actualidad de ese reclamo otorga nuevo sentido al cuestionamiento de la autonomía didáctica y la reinserción de la comprensión de los procesos formativos en la complejidad del fenómeno humano. Por tal motivo, la categoría de proyecto emerge como eje de gravitación del discurso demandando trascender la impronta gnoseológica del consenso triádico al situar una continuidad con un más allá del espacio de aula, espacio éste que obliga a "contaminar" la asepsia cultural del aula con dimensiones ineludibles de la vida extraescolar, entre las cuales la política aparece claramente relevada en Letelier no solo como "desocultamiento" (Souto, 1993, p. 45) sino como propuesta.

Su segunda gran contribución toca, en este sentido, a la delimitación de la didáctica como didáctica de objeto en tanto que centrada en los procesos de enseñanza y de aprendizaje de conocimientos, concepción que resulta cancelada cuando se atiende, como en el pensamiento de Letelier, a la reciprocidad de los horizontes de desarrollo y de aprendizaje, en una particular situación de producción que lo hace resaltar la dirección emancipadora de los proyectos pedagógico y didáctico.

21 Madoery (2012, p. 62) está haciendo esta aserción respecto del desarrollo como categoría originalmente económica, y alude con ella a los desarrollos teóricos latinoamericanos desde mediados del siglo XX como la teoría de la dependencia, la filosofía de la liberación, la pedagogía de la liberación entre otras. Este autor, sin embargo, no historiza los cuestionamientos a la idea de desarrollo en el pensamiento latinoamericano anterior, dentro del cual, tal vez, fuera posible encontrar otras coincidencias como las evidenciadas en el caso de Letelier. 
En términos generales, y dentro de sus propios alcances, en nuestra revisión de este autor parece confirmarse la hipótesis de Madoery respecto de que, en Latinoamérica, la reflexión en torno a la categoría de desarrollo, o el "desenvolvimiento" para Letelier, "cuestiona las bases epistemológicas del desarrollo al poner el foco en las relaciones de poder histórica y actualmente imperantes. Lo saca de su reducto económico y lo coloca en el amplio terreno de los procesos sociales"(Madoery, 2012, p. 63).

\section{REFERENCIAS}

Acosta, J. De procuranda indorum salute. Madrid: Fundación Ignacio Larramendi, 2011. [1. edição 1588]

Aguilera, F. Es tiempo de humanidades. Revista Chilena de Humanidades, Santiago de Chile: Universidad de Chile, n. 12, p. 15-25, 1991.

Ausubel, D.; Novak, J.; Hanesian, H. Psicología educativa: un punto de vista cogniscitivo. México, DF: Trillas, 1983.

Bain, A. La ciencia de la educación. Valencia: Biblioteca Profesional de Educación; Sociedad de Profesores, 1882.

Behetti, P. Fantasía didáctica y constitución subjetiva. In: Bordoli, E.; Blezio, C. (Comps.). El borde de lo (in) enseñable: anotaciones sobre una teoría de la enseñanza. Montevideo: Departamento de Publicaciones de la Facultad de Humanidades y Ciencias de la Educación, Universidad de la República, 2007.

Bordoli, E. La tríada del saber en lo curricular. Apuntes para una teoría de la enseñanza. In: _. Blezio, C. (Comps.). El borde de lo (in)enseñable: anotaciones sobre una teoría de la enseñanza. Montevideo: Departamento de Publicaciones, Facultad de Humanidades y Ciencias de la Educación, Universidad La República, 2007.

Camilloni, A.; Basabe, L.; Feeney, S. El saber didáctico. 1. reimpr. Buenos Aires: Paidós, 2008.

Carmagnani, M. Estado y sociedad en América Latina 1850-1930. Barcelona: Crítica, 1984.

Cerlettr, A. Repetición, novedad y sujeto en la educación: un enfoque filosófico y político. Buenos Aires: Editorial del Estante, 2008.

Chevallard, Y. La transposición didáctica: del saber sabio al saber enseñado. Tradução de Claudia Gilman. 3. ed. Buenos Aires: Aiqué Grupo Editor, 2009.

Сомте, A. Curso de filosofía positiva. Buenos Aires: Ediciones Orbis, 1984.

Fanon, F. Los condenados de la tierra. 1. ed. español. México, DF: Fondo de Cultura Económica, 1963.

Freire, P. Cartas a quien pretende enseñar. 4. ed. español. México DF: Siglo XXI, 1994. Galdames, L. Valentín Letelier y su obra: 1852-1919. Santiago: Universitaria, 1937.

Germán, G. Metapedagogía. 2. ed. Córdoba: Comunicarte, 2008.

Giroux, H. Teoría y resistencia en educación: una pedagogía para la oposición. 4. ed. México DF: Siglo XXI, 2004. 
Good, H.G. A history of western education. New York: The Macmillan Company, 1960. Gramsci, A. El materialismo histórico y la filosofía de Benedetto Croce. Buenos Aires: Ediciones Nueva Visión, 1971.

La Salle,J. B. Guía de las escuelas cristianas. Página del Distrito Lasallista de Medellín, s.f. Disponible en: <http://www.delasalle.edu.co/distrito/index.php?option=com_cont ent\&view=article\&id=20\&Itemid=13>. Acesso en: 18 marzo 2011.

Lander, E. Ciencias sociales: saberes coloniales y eurocéntricos. In: $\mathrm{La}$ colonialidad del saber: eurocentrismo y ciencias sociales, perspectivas latinoamericanas. Buenos Aires: CLACSO, 2000.

Letelier, V. La lucha por la cultura: miscelánea de artículos políticos y estudios pedagójicos. Santiago de Chile: Imprenta y Encuadernación Barcelona, 1895.

. Filosofía de la educación. 2. ed. Buenos Aires: Cabaut y Cía, 1927.

Litwin, E. El oficio de enseñar. Buenos Aires: Paidós, 2008.

Madoerr, O. El desarrollo como categoría política. Crítica y Emancipación, Buenos Aires: CLACSO, n. 7, p. 54-83, 2012.

Medina, J. El malestar en la pedagogía. El acto de educar desde otra identidad docente. Buenos Aires: Noveduc, 2006.

Narodoski, M. Infancia y poder: la conformación de la pedagogía moderna. Buenos Aires: AIQUÉ, 1994.

Nervi, M. L.; Nervi, H. ¿Existe la pedagogía?: hacia la construcción del saber pedagógico. Santiago de Chile: Editorial Universitaria, 2001.

Noguera, C.; Ramírez, D. Educar es gobernar: la educación como arte de gobierno. Cadernos de Pesquisa, São Paulo: Fundação Carlos Chagas; Campinas: Autores Associados, v. 42, n. 145, p. 14-29, jan./abr. 2012.

Pestalozzi, H. El método. Tradução de Lorenzo Luzuriaga. Madrid: Ediciones de la Lectura, 1800.

Cómo Gertrudis enseña a sus hijos. Tradução de Lorenzo Luzuriaga. 2. ed. Madrid: Ediciones de la Lectura, 1801.

Pizarro, C. La revolución de 1891, la modernización. Valparaíso: Ediciones Universitarias de Valparíso, 1971.

Rama, A. La ciudad letrada. Hanover: Ediciones del Norte, 1984.

Ramírez Necochea, H. Balmaceda y la contrarrevolución de 1891. 3. ed. Santiago de Chile: Editorial Universitaria, 1972.

Rojo, G. Las armas de las letras: ensayos neoarielistas. Santiago de Chile: LOM, 2008. .El campo cultural latinoamericano de la primera modernidad: 1870-1920. Santiago: Manuscrito, 2011.

Romeo, J. Perspectivas del curriculo en educación superior. Enfoques Educacionales, Chile: Departamento de Educación, Facultad Ciencias Sociales, Universidad de Chile, v. 1, n. 1, p. 56-72, 1998.

Rousseau, J.-J. Emilio, o de la educación. Madrid: Alianza Editorial, 1990.

SAID, E. Cultura e imperialismo. Barcelona: Anagrama, 2001. 
Souto, M. Hacia una didáctica de lo grupal. Buenos Aires: Miño y Dávila, 1993.

Spencer, H. La educación: intelectual, moral y física. 6. ed. New York: Appleton y Cía, 1912.

Subercaseaux, B. Fin de siglo: la época de Balmaceda. Santiago de Chile: Aconcagua, 1988.

Voloshinov, V. El signo ideológico y la filosofía del lenguaje. Buenos Aires: Ediciones Nueva Visión, 1976.

Vygotski, L. S. Pensamiento y lenguaje. Barcelona: Paidós, 1995.

\section{SOBRE EL AUTOR}

Adrián Rodrigo Baeza Araya es doctor en estudios latinoamericanos por la Universidad de Chile (Chile). Profesor de la misma institución.

E-mail: abaeza@uchile.cl 